\title{
Spectrometric study of condensed phase species of thorium- and palladium-based modifiers in a complex matrix for electrothermal atomic absorption spectrometry $\dagger$
}

\author{
M. A. Castro, ${ }^{a}$ A. J. Aller, ${ }^{* a}$ A. McCabe, ${ }^{b}$ W. E. Smith ${ }^{b}$ and D. Littlejohn* ${ }^{b}$ \\ Received 1st September 2006, Accepted 18th December 2006 \\ First published as an Advance Article on the web 12th January 2007 \\ DOI: $10.1039 / \mathrm{b} 612648 \mathrm{k}$
}

The chemical and morphological transformations of condensed phase species of a thorium-based modifier were studied over the temperature range $200-2500{ }^{\circ} \mathrm{C}$, without and with the presence of aluminium and silicon as matrix components, and in some instances, arsenic as an analyte element. A similar study was also conducted with palladium as the modifier, for comparison. Results were derived using scanning electron microscopy (SEM), energy dispersive (ED) X-ray spectrometry, Raman microanalysis and attenuated total reflectance (ATR) Fourier transforminfrared (FT-IR) spectrometry. Comparable results were found using pyrolytic and non-pyrolytic graphite platforms, with processes occurring at slightly higher temperatures on the pyrolytic graphite platform. With thorium as the modifier, metal oxides were the predominant species on the platform surface at relatively low temperatures $\left(<1500{ }^{\circ} \mathrm{C}\right)$, whereas metal phases became prevalent at high temperatures, when thorium and aluminium tended to behave independently from one other. Some spatial variations in the composition of the salt residues on different regions of the platform were observed (from the region closest to the slot in the tube, to the region furthest from the slot). Nonetheless, thorium metal remained on the graphite platform to higher temperatures than did aluminium metal. In the presence of arsenic, the existence of mixtures of thorium and arsenic oxides, just before the appearance temperature of gas phase arsenic atoms, was confirmed by SEM studies, ED X-ray spectra and Raman microanalysis. This suggests that any modifying effect of thorium on arsenic occurs while the modifier is in the oxide phase rather than in the metal phase. The presence of silicon added as silica, did not influence significantly the thermochemical behaviour of mixtures of thorium and aluminium. However, coexistence of silicon and arsenic oxides at the appearance temperature of the atomic absorption signal of arsenic was obtained, confirming that silicon can act as an internal modifier for arsenic. In the presence of palladium, aluminium exhibited greater interaction with the modifier;

consequently, aluminium metal was retained on the platform surface to higher temperatures than thorium, which could explain how interference effects of aluminium on e.g. arsenic are avoided or reduced. Similarly, there was evidence for interaction of palladium and arsenic in the reduced state. However, when aluminium and silicon were present, the transformation of the palladium oxide to the metallic state was affected, which could diminish the modifying benefits of palladium for arsenic in the presence of aluminium.

\section{Introduction}

A chemical modifier is often required to overcome interferences from matrix components in the determination of volatile analytes by electrothermal atomic absorption spectrometry (ETAAS). The most routinely selected chemical modifier has been palladium, used either singly or mixed with other metals. ${ }^{1-3}$ The stabilising effect of a palladium modifier is thought

\footnotetext{
${ }^{a}$ Department of Biochemistry, Area of Analytical Chemistry,

University of León,E-24071León, Spain.E-mail: dbbjaf@unileon.es

${ }^{b}$ Department of Pure and Applied Chemistry, University of

Strathclyde, 295 Cathedral Street, Glasgow, UK G1 IXL. E-mail:

d.littlejohn@strath.ac.uk

$\dagger$ Electronic supplementary information (ESI) available: Fig. S1-S6.

See DOI: $10.1039 / \mathrm{b} 612648 \mathrm{k}$
}

to be achieved through the formation of analyte-palladium binary compounds, ${ }^{4-8}$ or dissolution of the analyte in molten palladium. The main benefit of palladium-base modifiers is the increase in the pyrolysis and atomization temperatures that can be achieved for many relatively volatile elements. Other platinum group metals and oxide/carbide-forming elements, have also been used to good effect as modifiers in ETAAS. ${ }^{8-10}$ Thorium has been shown to work successfully when added in solution as a single chemical modifier for the determination of $\operatorname{arsenic}^{9,10}$ in samples containing aluminium, such as coal fly ashes. It is well known that aluminium can cause severe interferences in the determination of arsenic by ETAAS. ${ }^{11-15}$ The efficiency of thorium as an analyte stabiliser is thought to be based on the formation of stable oxides on the platform surface. However, the mechanism of analyte retention by the 
Table 1 Temperature program

\begin{tabular}{llllll}
\hline Parameter & Dry & Pyrolysis 1 & Pyrolysis 2 & Atomisation & Cleaning \\
\hline Temperature $/{ }^{\circ} \mathrm{C}$ & 150 & $200 \leftrightarrow 375$ & $200 \leftrightarrow 500$ & $200 \leftrightarrow 2500$ & $200 \leftrightarrow 2500$ \\
Ramp time $/ \mathrm{s}$ & 2 & 15 & 15 & 0 & 0 \\
Hold time $/ \mathrm{s}$ & 0 & 0 & Low & Off & 0 \\
Argon flow & Low & Medium & High \\
\hline
\end{tabular}

chemical modifier has still to be confirmed unequivocally. Furthermore, little is known about the chemical interaction of the modifier with components in the sample matrix.

In this work, condensed phase thorium species formed on a graphite platform during the heating of thorium nitrate, added in solution or used as a permanent modifier, have been studied. Experiments were carried out over a wide temperature range with thorium in an increasingly more complex matrix, containing arsenic as the analyte, aluminium nitrate as an interferent, and silica as a concomitant species. The main objectives of the study were to investigate the mechanism of the thermal transformation of the thorium species and to assess the effects of possible interactions between the species. It was anticipated that the information derived would contribute to the understanding of both modification and interference effects in separate studies on the determination of arsenic by ETAAS. Similar experiments were conducted using palladium as the modifier. Characterization of the condensedphase species followed similar methodology to that described elsewere, ${ }^{16}$ and involved analysis by scanning electron microscopy (SEM), energy dispersive (ED) X-ray spectrometry, Raman microanalysis and attenuated total reflectance (ATR) Fourier transform-infrared (FT-IR) spectrometry. Electron probe techniques have proved to be very powerful tools for morphological visualization and chemical identification of solid micro-particles on the surface of graphite platforms. ${ }^{15-}$ 22 However, the information derived mainly concerns the major transformations experienced by the matrix components and/or chemical modifiers in the injected solution, and only relatively high concentrations of the analyte. Other authors have used alternative techniques including Rutherford backscattering, synchrotron X-ray absorption spectroscopy, and mass spectrometry, among others, ${ }^{23-26}$ for evaluation of condensed-phase species on a graphite platform over a shorter temperature range than considered in this study.

\section{Experimental}

\section{Instruments and operating conditions}

Electrothermal atomic absorption spectrometry. A Thermo Jarrel Ash atomic-absorption spectrophotometer (SH 11), equipped with a CTF-188 graphite atomizer and SmithHieftje background correction, was used. The operation of the CTF-188 atomiser and calibration of the temperature settings with an optical pyrometer have been described previously. ${ }^{16,20-22}$ Standard uncoated rectangular graphite tubes, and standard pyrolytic graphite coated graphite platforms and standard uncoated non-pyrolytic graphite platforms were used for atomization. The platform was inserted into the tube via a slot along the side of the tube, below the sample injection hole (Fig. S1) $\dagger$ A syringe was used to inject manually $10 \mu \mathrm{l}$ of the solutions into the graphite atomizer at room temperature. The temperature programme of the atomiser, shown in Table 1, was always fully completed from the dry to cleaning stages. However, the temperatures for the pyrolysis, atomisation and cleaning stages were raised in consecutive cycles over the range 200-2500 ${ }^{\circ} \mathrm{C}$. A combination of "gas on" (Ar, $99.995 \%$ purity) and "gas off" modes was used in order to mimic the normal situation of analysis by ETAAS. Once the selected maximum platform temperature had been held for the chosen time, the platform was cooled to room temperature and placed in a dessicator until analysis of the dried deposit on the surface.

The thorium deposition process carried out to obtain the permanent modifier conditions was as follows: $40 \mu \mathrm{l}$ of a thorium solution $\left(1000 \mathrm{mg} \mathrm{l}^{-1}\right)$ was deposited on to the graphite platform and subjected to a series of heating cycles of increasing temperature $\left(500,1000,1500,1800{ }^{\circ} \mathrm{C}\right.$ and $2500{ }^{\circ} \mathrm{C}$ ). The thorium deposition process was repeated five times and then the platform surface was examined with scanning electron microscopy (SEM) to ensure that the chemical composition and morphological characteristics of the solid residue were as expected.

Scanning electron microscopy. Electron microprobe analysis of the graphite atomizer surface was performed with a JEOL scanning electron microscope (Model JSM-6100), equipped with an energy-dispersive X-ray detecting system (LINK) operated under the recommended conditions $(15 \mathrm{kV}$ acceleration voltage and $5 \mathrm{nA}$ probe current). The spatial coincidence of two selected elements in the spatial distribution maps has been indicated in the figures using red and green dots.

Raman spectrometry. The Raman spectra were obtained using a Renishaw spectrometer fitted with a CCD detector and an Olympus optical microscope. Raman spectrometry measurements were performed at room temperature using the $514.5 \mathrm{~nm}$ line of an argon ion laser as the excitation source, at a nominal power level of $100 \%$; in some instances, the power had to be reduced due to saturation of the detector. The experimental conditions were $10 \mathrm{~s}$ accumulation time, 1 min acquisition time, a $\times 20$ objective and a scan range of 200-4000 $\mathrm{cm}^{-1}$. Raman results were processed using GRAMS20 software.

Fourier transform infrared spectrometry. Infrared spectra in the region $400-5000 \mathrm{~cm}^{-1}$ were recorded on a Perkin Elmer System 2000 Fourier transform spectrometer (Norwalk, CT, USA) equipped with an air-cooled deuterium tryglicine sulfate (DTGS) detector. The attenuated total reflection (ATR) measurements were made with a Perkin Elmer in-compartment 
HATR ACCY-FLAT (2000) accessory equipped with flat topplate fitted with a 25 reflection, $45^{\circ}, 50 \mathrm{~mm} \mathrm{ZnSe}$ crystal. The $\mathrm{ZnSe}$ crystal was scanned as the background; for each spectrum, 400 scans were co-added at a spectral resolution of $2 \mathrm{~cm}^{-1}$. In an effort to minimize problems from avoidable baseline shifts, the spectra were baseline-corrected and normalized using the maximum-minimum normalization function in the OPUS software.

A pH-meter (Crison model Digit 505) was used to measure the acidity of the aqueous phase when necessary. A Mettler AE 240 semi-micro analytical balance (sensitivity $\pm 0.01 \mathrm{mg}$ ) was used to weigh the chemicals.

\section{Chemicals}

Thorium, aluminium and arsenic stock solutions $(10000 \mu \mathrm{g}$ metal $\mathrm{ml}^{-1}$ ) were prepared by dissolving a suitable amount of thorium nitrate, aluminium nitrate and arsenic (III) oxide, respectively, in an appropriate volume of distilled, de-ionized water (resistivity $18 \mathrm{M} \Omega \mathrm{cm}$ ). Palladium stock solutions (10 $000 \mu \mathrm{g}$ metal $\mathrm{ml}^{-1}$ ) were obtained by dissolving palladium chloride in $1.0 \mathrm{ml}$ concentrated $\mathrm{HCl}(d=1.19$, and $37.9 \%$ $\mathrm{w} / \mathrm{w})$ and diluting with water. Silicon stock solutions (10 000 $\mu \mathrm{g}$ metal $\mathrm{ml}^{-1}$ ) were prepared by dissolving silica in the smallest possible amount of $0.1 \mathrm{M} \mathrm{NaOH}$ solution and diluting with water. Working solutions were prepared prior to their use by dilution of the stock solutions with distilled, de-ionized water. All chemicals used in this study were of analytical reagent grade and were obtained from Merck.

\section{Results and discussion}

Modifier-concomitant interactions: SEM and ED X-ray studies

Analysis of the element distribution maps of the solid residue on the non-pyrolytic graphite platforms indicates that when thorium nitrate alone was heated at temperatures up to $1500{ }^{\circ} \mathrm{C}$, thorium oxide was formed. At higher temperatures, thorium metal particles with negligible amounts of oxygen were produced. When mixtures of thorium and aluminium nitrates were heated up to $1500{ }^{\circ} \mathrm{C}$ on a non-pyrolytic platform, the element spatial distributions derived from the ED X-ray measurements suggest that a mixture of aluminium oxide and thorium oxide was produced, rather than a solid solution between aluminium and thorium, which was previously considered unlikely. ${ }^{27}$ However, the most characteristic morphological and chemical transformations of thorium and aluminium nitrates occurred above $1500{ }^{\circ} \mathrm{C}$. Over the temperature range $1500-2500{ }^{\circ} \mathrm{C}$, the element distribution maps of the salt residues were different on the regions of a non-pyrolytic graphite platform located closest to, intermediate from and furthest away from the slot on the tube (see Fig. $\mathrm{S} 1 \dagger$ and Fig. 1). The outer region on the platform surface is characterized by the predominance of small irregular particles of aluminium oxide that were progressively reduced to aluminium as the temperature was increased; these deposits only had very small amounts of associated thorium (Fig. 1A). In the intermediate region (i.e. the middle of the platform), the residues appeared to consist of a mixture of aluminium and thorium oxides, with the amount of aluminium decreasing as

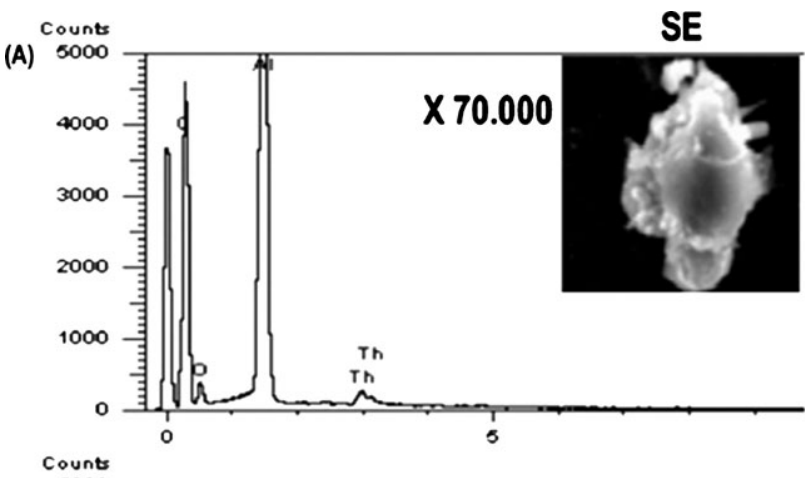

(B)
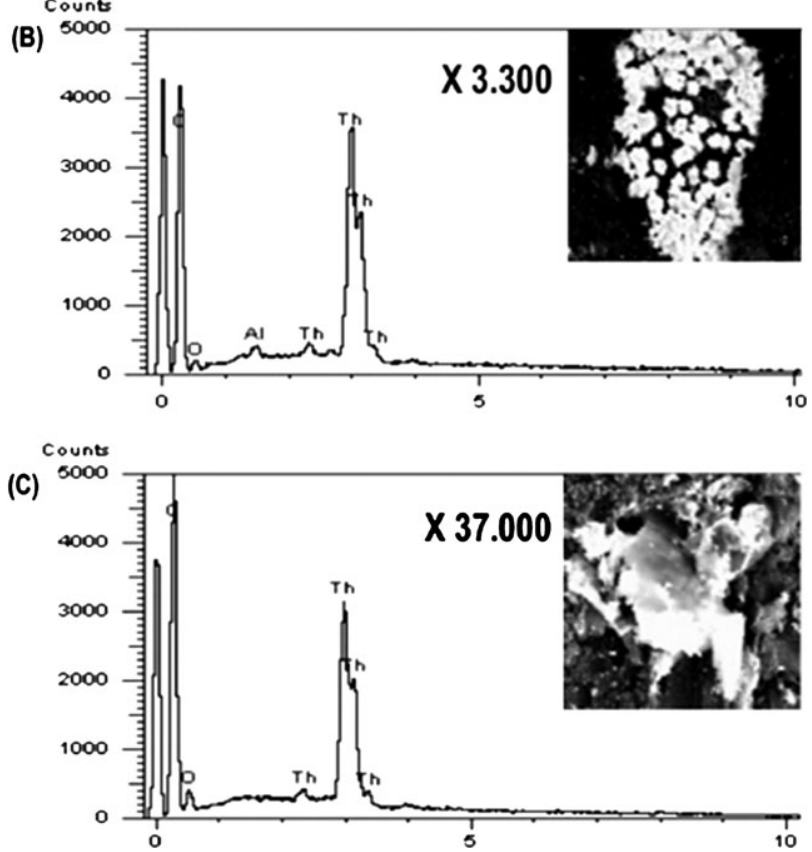

Fig. 1 ED X-ray spectra and secondary electron mappings from the (A) outer, (B) intermediate, and (C) inner regions of a non-pyrolytic graphite platform containing $100 \mu \mathrm{g}$ each of aluminium and thorium nitrates heated to $2000{ }^{\circ} \mathrm{C}$.

temperature was increased (Fig. 1B). The salt particles produced at $2000{ }^{\circ} \mathrm{C}$ in the region of the platform furthest from the slot were comprised predominantly of thorium with little or no oxygen or aluminium (Fig. 1C). There was also some evidence, in the element distribution maps, for an association of thorium and carbon on the particles formed at $2000{ }^{\circ} \mathrm{C}$. The spatial variation in the distribution of the elements may have been the result of differences in either the diffusion of the metal atoms into the graphite substrate, caused by an electric field or temperature gradient, ${ }^{28}$ or the effects of oxygen entering as air through the injection hole, or both.

The morphology of the solid residues varied markedly as indicated in Fig. 1, detecting also important changes in their composition: flowered spherical particles, comprising a mixture of aluminium and thorium oxides; doughnut shaped particles of between 5 and $20 \mu \mathrm{m}$ diameter, made up mainly of thorium metal; and irregular particles, also constituted by thorium. Many of the flowered spherical particles resembled keplerate-type molecules. ${ }^{29,30}$ These clusters can condense into a variety of polyoxometalates with a considerable variety of 
charge and framework architecture that exhibit large spherical cavities, making them attractive candidates to host Keggin ions. The formation of framework structures could be the reason for the stabilizing effect of certain modifiers (such as thorium) on metal analytes in ETAAS. Closer examination reveals that the flowered spherical particles comprise three superimposed layers that are different in their composition and morphology. The outer layer exhibits irregular thorium metal particles (Fig. S2A, a-f $\dagger$ ) and star-shaped features, also comprising mainly thorium (blue diamond, Fig. $\mathrm{S} 2 \mathrm{~B} \dagger$ ). Below the star-like features, the intermediate layer of the particles is mainly constituted by aluminium oxide with some thorium metal and/or thorium oxide (brown triangle, Fig. S2B $\dagger$ ). Below the intermediate layer, there is a third layer of mostly aluminium (green circle, Fig. $\mathrm{S} 2 \mathrm{~B} \dagger$ ).

When pyrolytic graphite platforms were used, the thermal transformations observed were generally comparable to those obtained with non-pyrolytic graphite. However, the platform had to be heated for longer (e.g. $4 \mathrm{~s}$ ) and/or to a slightly higher temperature to achieve the same chemical and morphological changes. With thorium nitrate alone, smaller particles $(1-13 \mu \mathrm{m})$ of thorium oxide were formed on pyrolytic graphite platforms than on a non-pyrolytic graphite surface (10$50 \mu \mathrm{m})$. When mixtures of thorium and aluminium nitrate were heated, a mixture of metal oxides also existed on pyrolytic graphite platforms heated up to $1500{ }^{\circ} \mathrm{C}$. Above $1500{ }^{\circ} \mathrm{C}$, spatial variations in the composition and morphology of the solid residues were also noted, although distinctions between the residues at the three regions on the platform, in relation to the slot in the tube, were not as clear.

Overall, variations in the morphology and chemical composition of the solid residues indicate that aluminium and thorium oxides undergo different, and perhaps independent, thermal transformations above $1500{ }^{\circ} \mathrm{C}$, which are probably influenced by temperature and oxygen concentration gradients existing in the graphite tube. At the higher temperatures, the residue is predominantly thorium. Consequently, through repeated injection and thermal treatment of a concentrated thorium solution, it is possible to build up layers of thorium metal on the surface of the platform and so produce a permanent modifier on the graphite (for both pyrolytic and non-pyrolytic platforms).

Silica exists in many types of sample such as coal fly ashes. The presence of silicon, as silica, altered slightly the thermal behaviour of the thorium modifier and the aluminium interferent, depending on the platform location and temperature. Up to about $1500{ }^{\circ} \mathrm{C}$, a mixture of metal oxides existed, forming spherical $(12-21 \mu \mathrm{m})$ and irregular $(27-52 \mu \mathrm{m})$ particles. However, at higher temperatures, changes in the morphology and chemical composition of the particles occurred, depending on the location on the platform; in general, these transformations occurred at lower temperatures than for the Al-Th mixture without silicon. In the outer region of the platform closest to the slot in the tube, spherical particles were predominant, mainly composed of a mixture of oxides (12-24 $\mu \mathrm{m})$ and smaller alumina particles $(2-6 \mu \mathrm{m})$ with occasionally very low amounts of thorium. In the inner region of the platform, thoria and silica were the prevalent species, but mainly occurred separately. Spherical particles containing both alumina and thoria could be identified, but were probably discrete chemical entities (Fig. S3†). All the elements (Al, $\mathrm{Si}$, Th) tended to behave independently as the atomiser temperature was increased, with the relative amounts varying with the location on the platform: outer region, $\mathrm{Al}>\mathrm{Si}>\mathrm{Th}$; intermediate region, $\mathrm{Si}>\mathrm{Al}>\mathrm{Th}$, and inner region, $\mathrm{Th} \geq$ $\mathrm{Si}>\mathrm{Al}$. Other observations were that the relative oxygen content of the particles decreased more at the inner region of the platform and that aluminium vaporised at lower temperatures than thorium and silicon, which were only produced from the corresponding oxides at very high temperatures. These observations indicate that the modifying attributes of thorium are not likely to be affected by the presence of aluminium and silicon in samples. Also, the vaporisation of aluminium is not affected by thorium (i.e. aluminium is not retained by thorium).

When thorium was replaced by palladium, the chemical transformations observed were quite similar up to about 1300$1500{ }^{\circ} \mathrm{C}$. At higher temperatures, metal (Pd, Al) oxides were transformed into the corresponding metal phases, particularly from small particles (Fig. S4 $\dagger$ ), but with some differences in the transformation rate for each element. The spatial variation in the distribution of aluminium on the platform in the presence of palladium was not as pronounced as for addition of thorium as the modifier. Palladium metal appeared on the graphite surface at lower temperatures than aluminium metal (Fig. S4 $\uparrow$ ). It was found previously that complete transformation of the $\mathrm{PdO} \rightarrow \mathrm{Pd}$ above $950{ }^{\circ} \mathrm{C}$ yielded metal particles, which are thought to be very difficult to re-oxidize upon cooling. ${ }^{31}$ At $1800{ }^{\circ} \mathrm{C}$, some alumina particles appeared to be surrounded by a few protuberances of Al-Pd alloy (Fig. $\mathrm{S} 4 \dagger)$. The formation of Al-Pd alloy became more pronounced at $2000{ }^{\circ} \mathrm{C}$, although there were areas of the platform surface containing some palladium metal particles and separate aluminium metal phases, which remained until higher temperatures than for the thorium case. As observed for the Al-Th system, the presence of silicon only slightly affected the thermochemical behaviour of Al-Pd. In general, the amount of aluminium and oxygen in the salt deposits decreased with temperature, mainly above $1800{ }^{\circ} \mathrm{C}$, and this was more pronounced at the inner region of the platform than for the outer region, closest to the slot in the tube (Fig. S5 †). In comparison with the thorium experiments, aluminium metal was more commonly observed in the presence of palladium and spatial separation of the three elements (Al, Si and the modifier) was also less frequently encountered than in the presence of thorium. Elemental aluminium, palladium and silicon usually appeared at about $1800{ }^{\circ} \mathrm{C}$, but the relative amount of aluminium metal seemed to be greater than when thorium was used as the modifier. Formation of Al-Pd alloys as small particles only occurred once the metals had been produced. When aluminium vaporised from the alloy at higher temperatures, there was evidence that silicon and palladium combined in some particles (Fig. S5†). The observations with palladium present in the mixture rather than thorium, indicate that there are greater modifier-aluminium interactions with palladium than for thorium, which may be a reason for the effect on palladium on the extent of aluminium interference on arsenic. 


\section{Modifier-concomitant interactions: vibrational spectrometric studies}

Raman spectra were obtained of salt residues produced at different temperatures on graphite platforms. In general, the results confirm the interpretation of the ED X-ray and SEM measurements with some additional findings. Fig. 2A shows that the characteristic peak of thorium oxide, ${ }^{32}$ at $460 \mathrm{~cm}^{-1}$, decreases in magnitude when $100 \mu \mathrm{g}$ thorium nitrate was heated on a pyrolytic graphite platform to temperatures from 1000 to $2500{ }^{\circ} \mathrm{C}$, owing to formation of thorium metal. Similar observations were made when thorium and aluminium nitrates were heated together, and when producing a coating of a permanent thorium modifier on the platform. When Raman spectra were taken at the different regions of a platform heated to $1800{ }^{\circ} \mathrm{C}$, thorium oxide was located mainly at the intermediate and inner regions of the platform, but not at the outer region, closest to the slot (Fig. 2B), where the amount of thorium found to be negligible. There was no evidence for the transformation of hydroxyaluminium species into aluminium oxide, as the Raman spectra do not contain the typical peaks assigned to Al-O-Al skeletal flexing vibrations. ${ }^{33}$

The FTIR spectra of the solid residues on pyrolytic graphite platforms heated to different temperatures are shown in Fig. 3. The FT-IR spectra of the residues produced from thorium
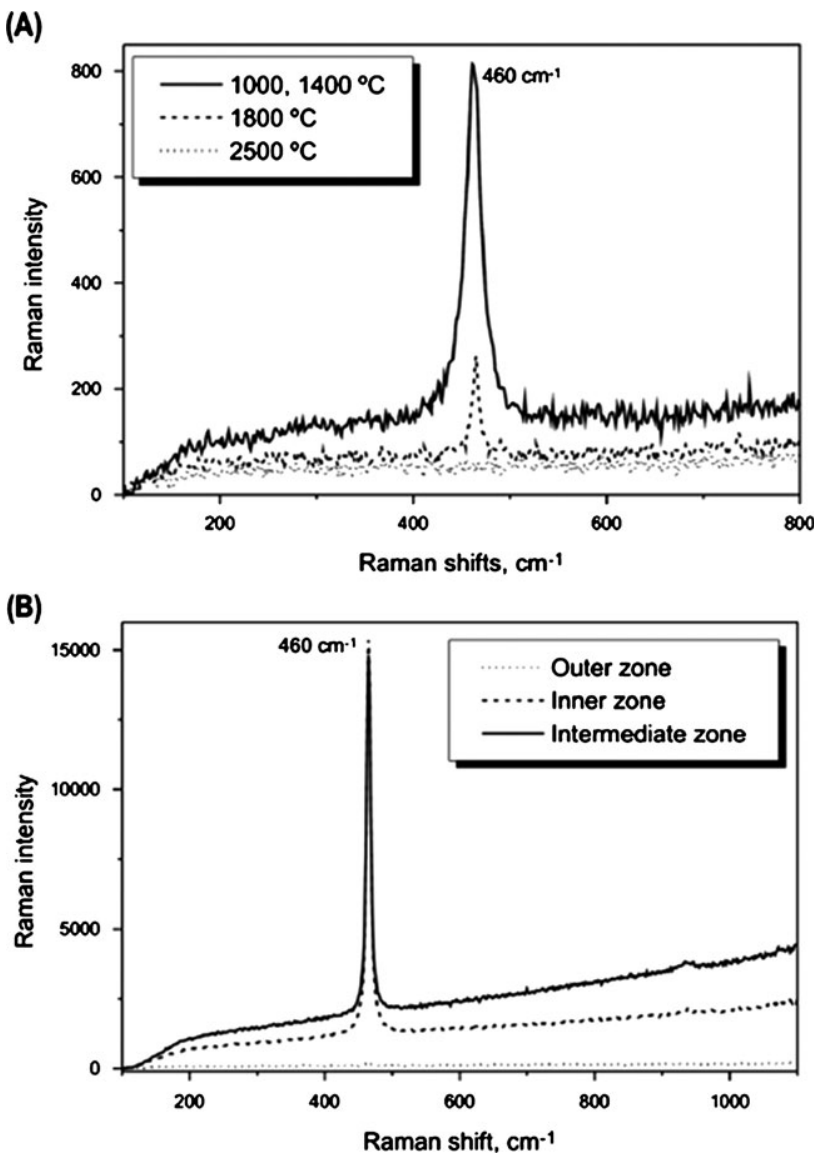

Fig. 2 Raman spectra of (A) $100 \mu \mathrm{g}$ of thorium (as nitrate) on pyrolytic graphite platforms heated to different temperatures and (B) $100 \mu \mathrm{g}$ each of aluminium and thorium nitrates on three different locations of a non-pyrolytic graphite platform heated to $1800{ }^{\circ} \mathrm{C}$.

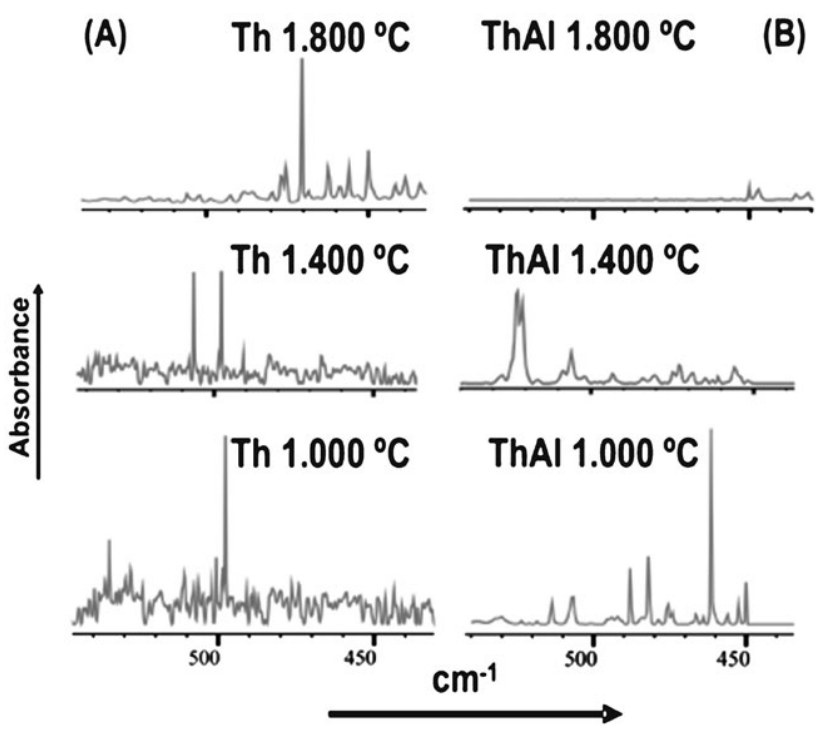

Fig. 3 FT-IR absorbance spectra of the solid residue from a large area of a graphite platform containing (A) $100 \mu \mathrm{g}$ of thorium nitrate and (B) $100 \mu \mathrm{g}$ each of aluminium and thorium nitrates heated to $1000{ }^{\circ} \mathrm{C}, 1400{ }^{\circ} \mathrm{C}$ and $1800{ }^{\circ} \mathrm{C}$.

nitrate (Fig. 3A) have peaks at $498 \mathrm{~cm}^{-1}\left(1000{ }^{\circ} \mathrm{C}\right), 498$ and $508 \mathrm{~cm}^{-1}\left(1400{ }^{\circ} \mathrm{C}\right)$ and $472 \mathrm{~cm}^{-1}\left(1800{ }^{\circ} \mathrm{C}\right)$, suggesting the presence of thorium oxide at the lower temperatures ${ }^{34}$ and the existence of some crystalline thorium metal at higher temperatures. The FT-IR spectrum from the thorium-aluminium salt residue shows bands at $462 \mathrm{~cm}^{-1}$ and other less intense peaks at $482,488,508$ and $515 \mathrm{~cm}^{-1}$ at $1000{ }^{\circ} \mathrm{C}$ (Fig. 3B), which are characteristic of $\mathrm{Th}-\mathrm{O}$ bands in $\mathrm{ThO}_{2}$ lattices. ${ }^{34}$ At $1400{ }^{\circ} \mathrm{C}$, the FTIR spectrum has weak bands at 506,521 and $523 \mathrm{~cm}^{-1}$, while at $1800{ }^{\circ} \mathrm{C}$ the previously identified peaks were not seen (Fig. 3B). Absorption bands of aluminium species, as well as peaks attributed to $\mathrm{Th}-\mathrm{Al}$ vibrations, ${ }^{35}$ were not observed.

When silicon was added to the mixtures $\mathrm{Th}-\mathrm{Al}$ and $\mathrm{Pd}-\mathrm{Al}$ and submitted to the same thermal treatments, the presence of silica at low temperatures and silicon at high temperatures was confirmed by Raman spectra ${ }^{36,37}$ (Fig. 4 and 5). Peaks at

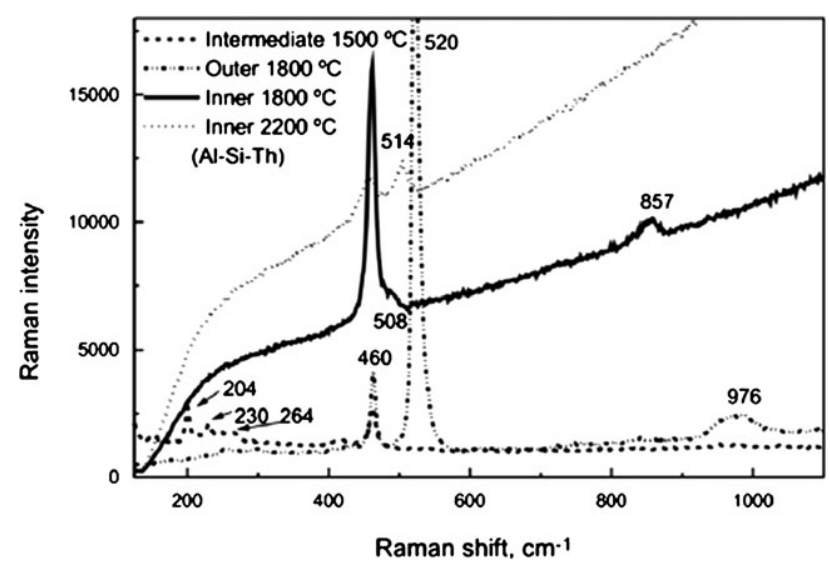

Fig. 4 Raman spectra of three different locations of pyrolytic graphite platforms containing $100 \mu \mathrm{g}$ each of aluminium and thorium nitrates and $100 \mu \mathrm{g}$ silicon, heated to 1500,1800 and $2200{ }^{\circ} \mathrm{C}$. 


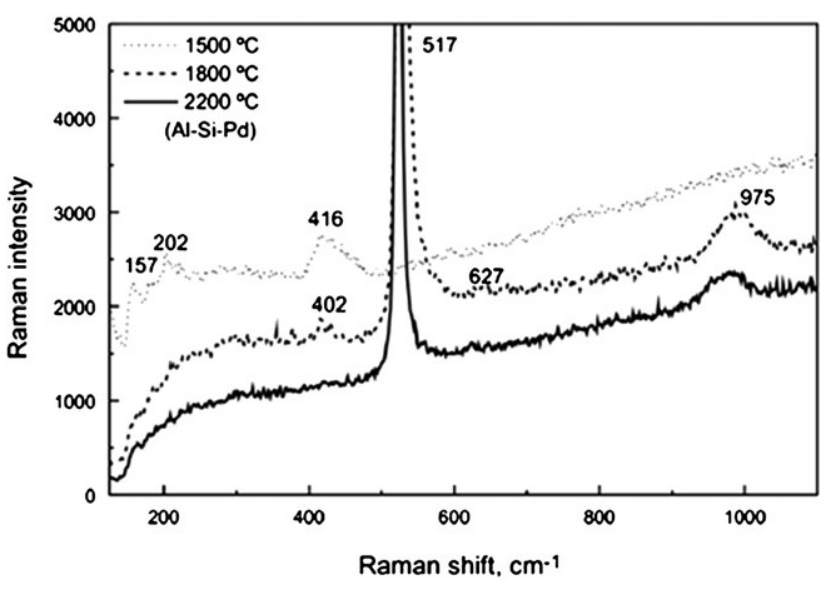

Fig. 5 Raman spectra of pyrolytic graphite platforms containing $100 \mu \mathrm{g}$ each of aluminium nitrate and palladium chloride, and $100 \mu \mathrm{g}$ silicon, heated to 1500,1800 and $2200{ }^{\circ} \mathrm{C}$.

about 157, 202/204, and $406 \mathrm{~cm}^{-1}$ characterize the existence of silica, while features at $517-520 \mathrm{~cm}^{-1}$ and $468 / 480 \mathrm{~cm}^{-1}$ confirm the formation of polycrystalline silicon films and amorphous silicon, respectively. However, transformation to silicon carbide seems to be also plausible at high temperatures $\left(1800\right.$ and $\left.2200{ }^{\circ} \mathrm{C}\right)$, as confirmed by the peak at $976 \mathrm{~cm}^{-1}$. 38,39 Alumina and thoria phases were also confirmed in the presence of silicon. No metal interactions seem to occur for aluminium and thorium, confirming independent behaviour at high temperatures after reduction to the corresponding metal.

\section{Modifier-analyte interactions}

It was not possible to make measurements of arsenic species at typical analyte concentrations with the surface analysis techniques here used. However, measurements were made with higher amounts of arsenic to derive some information about possible interactions between the modifier (Th or Pd) and the analyte, with and without the presence of silicon. SEM studies and ED X-ray spectra demonstrated the coexistence of thorium, oxygen and arsenic, just before the appearance temperature $\left(1200-1300^{\circ} \mathrm{C}\right)$ of gas phase arsenic atoms (Fig. 6A). It is likely, therefore, that interactions between thorium and arsenic take place mainly through the formation of a mixture of oxides, as the $\mathrm{Th} / \mathrm{O}$ intensity ratios derived from ED X-ray spectra are lower when arsenic is present. The existence of mixtures of thorium oxide and arsenic oxide was also confirmed by Raman spectrometry (Fig. 7A). The peak at $465 \mathrm{~cm}^{-1}$ is characteristic of thorium oxide, whilst the peaks at 258,707 and $795 \mathrm{~cm}^{-1}$ were assigned to amorphous arsenic, As- $\mathrm{OH}$ and $\mathrm{As}-\mathrm{O},{ }^{40,41}$ respectively. Arsenic oxide was also found in the presence of aluminium alone, as well as for $\mathrm{Th} / \mathrm{Al}$ and $\mathrm{Th} / \mathrm{Al} / \mathrm{Si}$ mixtures.

When thorium was replaced by palladium, results obtained with ED X-ray spectrometry confirmed the hypothesis that As-Pd interactions take place in the absence of oxygen, particularly for small solid particles, at the appearance temperature of the gas phase arsenic atoms $\left(\sim 1300{ }^{\circ} \mathrm{C}\right)$, when only both elements are in the atomiser (Fig. 6B). It was also
(A)

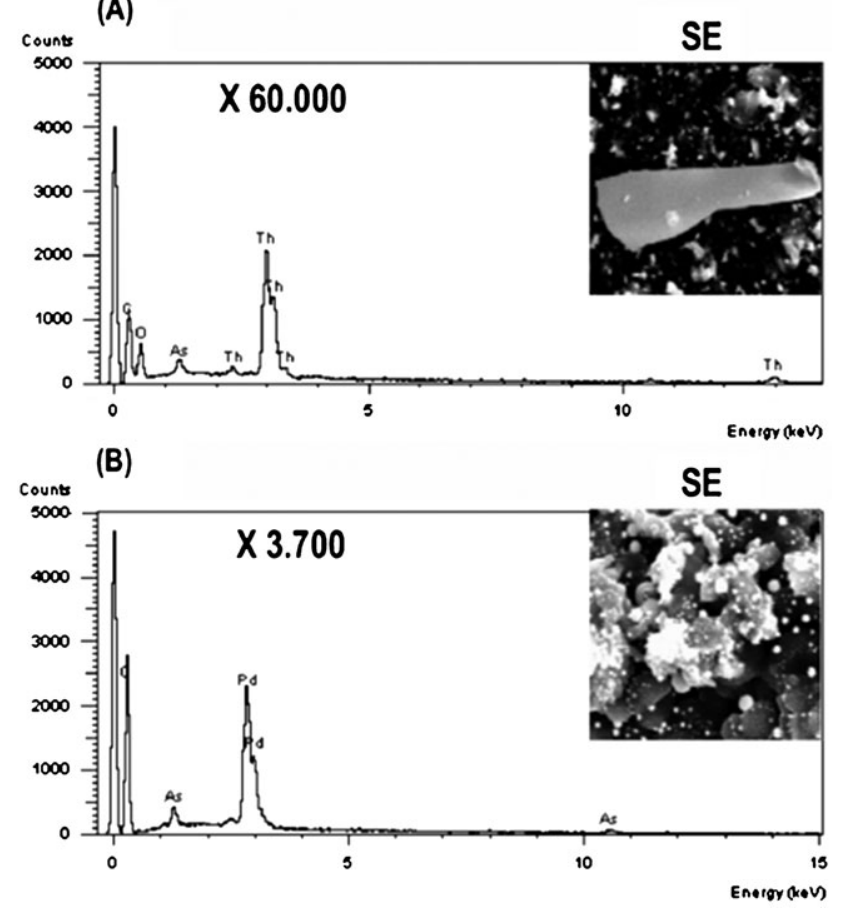

Fig. 6 ED X-ray spectra of pyrolytic graphite platforms containing (A) $100 \mu \mathrm{g}$ of thorium nitrate and $500 \mathrm{ng}$ of arsenic and (B) $100 \mu \mathrm{g}$ palladium chloride and $500 \mathrm{ng}$ arsenic, heated to $1200{ }^{\circ} \mathrm{C}$.

observed with Raman spectrometry that palladium was generally present as palladium metal, although slight surface oxidation seemed to occur as evidenced by a peak at $636 \mathrm{~cm}^{-1} .42$ The existence of PdO crystals on areas of the platform close to the injection slot, where oxygen is more accessible, was confirmed by the appearance of a characteristic peak at $651 \mathrm{~cm}^{-1}$ (Fig. 7B). ${ }^{43}$ Results for palladium-arsenic interactions derived in the presence of aluminium (and silicon) showed the spatial coexistence of oxygenated metal species (Fig. S6A $\dagger$ ) at $800{ }^{\circ} \mathrm{C}$. Palladium oxide is mixed together with alumina and some chlorine, as palladium chloride was the salt used. This suggests that the behaviour of palladium as a chemical modifier may be altered by the presence of some concomitants.

In a similar way, evidence for interaction of silicon with arsenic was also obtained. Mixtures of silicon and arsenic oxides were indicated by the spatial coexistence of the elements on the platform, as illustrated by SEM and ED-X ray spectrometry, as well as by Raman spectra taken from the same location of the platform (Fig. S6B $\dagger$ ) heated to $800^{\circ} \mathrm{C}$. Raman peaks at $158,258,419$ and $1016 \mathrm{~cm}^{-1}$ are indicative of the existence of some silica phases, while bands at 707 and 801 $\mathrm{cm}^{-1}$ confirm the presence of As-OH and As-O species (Fig. $\mathrm{S} 6 \mathrm{~B} \dagger$ ). It would appear that silicon as a concomitant species can act as an internal chemical modifier for arsenic.

\section{Conclusions}

Analyses of salt particles on the surface of platforms heated to different temperatures have allowed observation of the morphological and chemical transformation of thorium and 

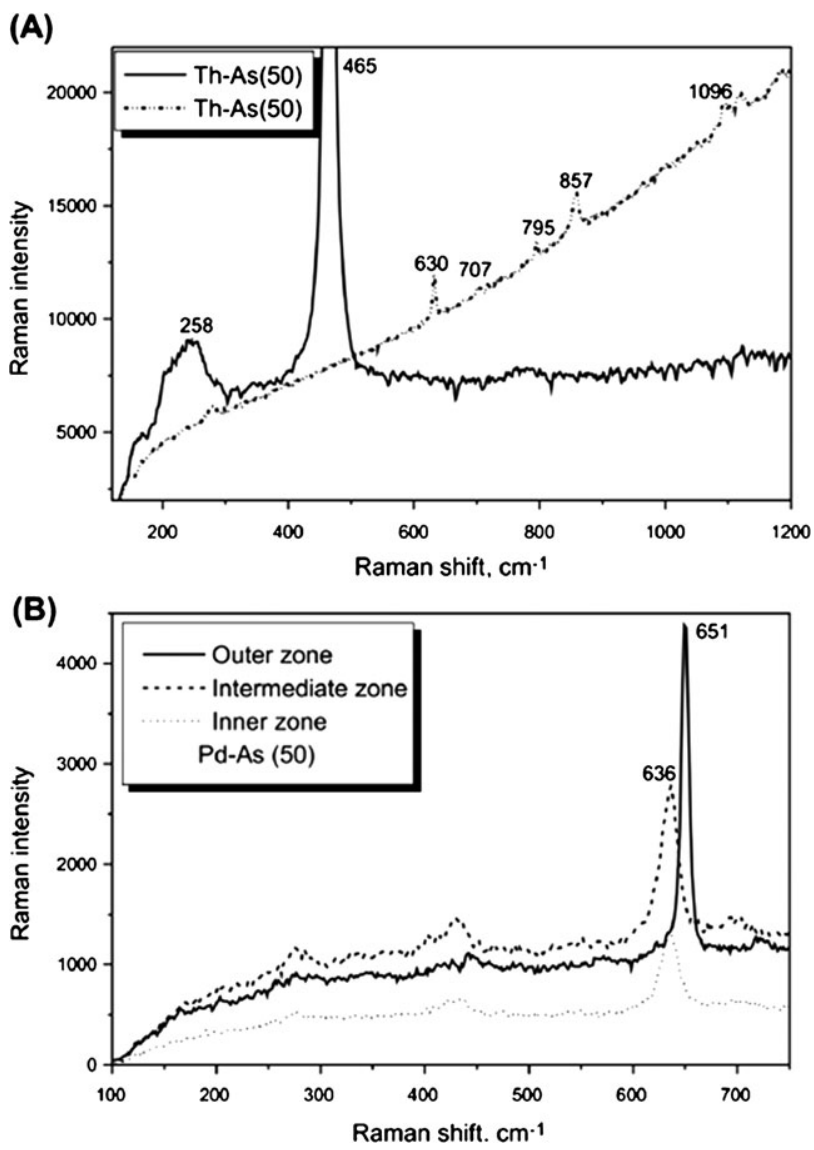

Fig. 7 Raman spectra from different locations of pyrolytic graphite platforms containing (A) $100 \mu \mathrm{g}$ of thorium nitrate and $500 \mathrm{ng}$ arsenic and (B) $100 \mu \mathrm{g}$ palladium chloride and $500 \mathrm{ng}$ arsenic, heated to $1200{ }^{\circ} \mathrm{C}$.

palladium modifiers, with and without the presence of aluminium and silicon as concomitant species. The study has also provided some information on the interaction of each modifier with arsenic and how this could influence interference effects of aluminium on determination of arsenic by ETAAS, although the mass of arsenic used in the study was higher than in normal measurements with ETAAS. A main conclusion is that the modifying effect of palladium could be affected by the presence of concomitant species more than that of thorium, although this will be investigated further through a separate study.

This investigation has shown that the primary modifying effect of thorium involves the oxide and that of palladium, the metal. The latter finding was expected and agrees generally with the conclusions of other authors ${ }^{4-8}$ for a similar situation, where the most plausible mechanism of action is reduction of arsenic oxide by the palladium modifier. ${ }^{5}$ No dissociative chemisorption of the analyte compounds on the surface of palladium metal ${ }^{4}$ and no graphite-arsenic-palladium interactions ${ }^{6}$ seem to contribute strongly to the stabilization process. SEM and ED-X ray measurements show that in the presence of aluminium, palladium forms $\mathrm{Pd}-\mathrm{Al}$ species that result in the aluminium remaining on the platform to higher temperatures than achieved with thorium, where no direct interaction was observed. However, in the presence of silicon, added as silica, the chemical transformation of palladium was disrupted, with evidence of the association of palladium, aluminium and silicon. Interestingly, there was also some indication that silicon could have a modifying action on arsenic. The adverse effect of concomitant species on the modifying action of palladium has also been revealed in preliminary experiments involving addition of 1-3 M concentrations of nitric acid to sample solutions. The presence of the acid caused the oxide of palladium to persist, adversely affecting the control of the interference effects of aluminium on arsenic; in contrast, the efficacy of the thorium was less affected by nitric acid, as the modifier acts through formation of the oxide. These observations require further investigation and results will be reported in a complementary paper.

\section{References}

1 Shan Xiao-Quan, Ni Zhe-Ming and Li Zhang, Anal. Chim. Acta, 1983, 151, 179-185.

2 Ni Zhe-Ming and Shan Xiao-Quan, Spectrochim. Acta, Part B, 1987, 42, 937-949.

3 G. Schlemmer and B. Welz, Spectrochim. Acta, Part B, 1986, 41, $1157-1165$.

4 B. V. L'vov, Spectrochim. Acta, Part B, 2000, 55, 1659-1668.

5 A. B. Volynsky, Spectrochim. Acta, Part B, 2000, 55, 103-150.

6 H. M. Ortner, E. Bulska, U. Rohr, G. Schlemmer, S. Weinbruch and B. Welz, Spectrochim. Acta, Part B, 2002, 57, 1835-1853.

7 A. B. Volynsky and M. T. C. de Loos-Vollebregt, Spectrochim. Acta, Part B, 2005, 60, 1432-1441.

8 A. B. Volynsky and R. Wennrich, Spectrochim. Acta, Part B, 2002, 57, 1301-1316.

9 S. K. Thulasidas, M. J. Kulkarni, N. K. Porwal, A. G. Page and M. D. Sastry, Anal. Lett., 1988, 21, 265-278.

10 M. A. Castro, C. García-Olalla, L. C. Robles and A. J. Aller, Spectrochim. Acta, Part B, 2002, 57, 1-14.

11 B. V. L'vov, J. Anal. At. Spectrom., 1987, 2, 95-104.

12 B. V. L'vov, L. K. Polzik, N. P. Romanova and A. I. Yuzefovskii, J. Anal. At. Spectrom., 1990, 5, 163-169.

13 J. A. Holcombe, D. L. Styris and J. D. Harris, Spectrochim. Acta, Part B, 1991, 46, 629-639.

14 M. M. Lamoureux, C. L. Chakrabarti, J. C. Hutton, A. Kh. Gilmutdinov, Y. A. Zakharov and D. C. Grégoire, Spectrochim. Acta, Part B, 1995, 50, 1847-1867.

15 M. A. Castro and A. J. Aller, Spectrochim. Acta, Part B, 2003, 58, 903-920.

16 M. A. Castro, A. J. Aller, A. McCabe, W. E. Smith and D. Littlejohn, J. Anal. At. Spectrom., 2005, 20, 385-394.

17 U. Rohr, H. M. Ortner, G. Schlemmer, S. Weinbruch and B. Welz, Spectrochim. Acta, Part B, 1999, 54, 699-718.

18 E. Bulska, B. Thybusch and H. M. Ortner, Spectrochim. Acta, Part $B, 2001$, 56, 363-373.

19 H. M. Ortner, U. Rohr, G. Schlemmer, S. Weinbruch and B. Welz, Spectrochim. Acta, Part B, 2002, 57, 243-260.

20 M. A. Castro, J. C. Feo and A. J. Aller, J. Anal. At. Spectrom., 2003, 18, 260-267.

21 M. A. Castro, K. Faulds, W. E. Smith, A. J. Aller and D. Littlejohn, Spectrochim. Acta, Part B, 2004, 59, 827-839.

22 M. A. Castro, K. Faulds, W. E. Smith, A. J. Aller and D. Littlejohn, Spectrochim. Acta, Part B, 2004, 59, 1935-1942.

23 V. Majidi and J. D. Robertson, Spectrochim. Acta, Part B, 1991, 46, 1723-1733.

24 M. M. Lamoureux, J. C. Hutton and D. L. Styris, Spectrochim. Acta, Part B, 1998, 53, 993-1002.

25 V. Majidi, R. G. Smith, N. Xu, M. W. McMahon and R. Bossio, Spectrochim.Acta, Part B, 2000, 55, 1787-1821.

26 D. L. Styris, L. J. Prell and D. A. Redfield, Anal. Chem., 1991, 63, 503-507.

27 Ming-min Shen, Yu-hai Hu, Hai-yang Zhu, Tian-dong Liu, Shuting Wei, Lin Dong and Yi Chen, J. Colloid Interface Sci., 2003, 257, 408-411.

28 T. Ichinokawa, H. Itoh and Y. Sakai, J. Anal. At. Spectrom., 1999, 14, 405-408. 
29 A. Müller, P. Kögerler and C. Kuhlmann, Chem. Commun., 1999, 15, 1347-1358.

30 A. Müller and S. Roy, Coord. Chem. Rev., 2003, 245, 153-166.

31 A. K. Datye, J. Bravo, T. R. Nelson, P. Atanasova, M. Lyubovsky and L. Pfefferle, Appl. Catal., A, 2000, 198, 179-196.

32 S. Dash, A. Singh, P. K. Ajikumar, H. Subramanian, M. Rajalakshmi, A. K. Tyagi, A. K. Arora, S. V. Narasimhan and B. Raj, J. Nucl. Mater., 2002, 303, 156-168.

33 R. Krishan, R. Kesavamoorthy, S. Dash, A. K. Tyagi and B. Raj, Scr. Mater., 2003, 48, 1099-1104.

34 S. A. Mahmoud, Solid State Sci., 2002, 4, 221-228.

35 D. Voll, P. Angerer, A. Beran and H. Schneider, Vib. Spectrosc., 2002, 30, 237-243.

36 Xiang-Sheng Bo, Nan Yao, Sean R. Shieh, T. S. Duffy and J. C. Sturm, J. Appl. Phys., 2002, 91, 2910-2915.
37 Y. W. Wang, C. H. Liang, G. W. Meng, X. S. Peng and L. D. Zhang, J. Mater. Chem., 2002, 12, 651-653.

38 A. J. Steckl, J. Devrajan, S. Tlali, H. E. Jackson, C. Tran, S. N. Gorin and L. M. Ivanova, Appl. Phys. Lett., 1996, 69, 38243826.

39 J.-Ch Panitz and A. Wokaun, Appl. Spectrosc., 1998, 52, 12521254.

40 Y. Takagaki, E. Wiebicke, M. Ramsteiner, L. Däweritz and K. H. Ploog, Appl. Phys. A: Mater. Sci. Process., 2003, 76, 837-840.

41 S. Goldberg and C. T. Johnston, J. Colloid Interface Sci., 2001, 234, 204-216.

42 J. R. McBride, K. C. Hass and W. H. Weber, Phys. Rev. B: Condens. Matter, 1991, 44, 5016-5028.

43 K. Otto, C. P. Hubbard, W. H. Weber and G. W. Graham, Appl. Catal., B, 1992, 1, 317-327. 